\title{
Erratum to: Studies on the phase I metabolism of the new designer drug 3-fluoromethcathinone using rabbit liver slices
}

\author{
Evelyn Pawlik • Gerd Plässer • Hellmut Mahler • \\ Thomas Daldrup
}

Published online: 6 October 2011

(C) Springer-Verlag 2011

\section{Erratum to: Int J Legal Med}

DOI 10.1007/s00414-011-0601-6

Figure 4 as published in the original version of this article was unfortunately incomplete.

The Publisher apologizes for this error, which was introduced inadvertently by the Publisher during the publication process. The correct figure is given below.

The online version of the original article can be found at http://dx.doi. org/10.1007/s00414-011-0601-6.

E. Pawlik $\cdot$ T. Daldrup

Institute of Legal Medicine, Heinrich-Heine University,

Duesseldorf, Germany

G. Plässer $\cdot$ H. Mahler

State Bureau of Criminal Investigation, Nordrhein-Westfalen,

Duesseldorf, Germany

H. Mahler $(\square)$

Landeskriminalamt NRW,

Kriminalwissenschaftliches und-Technisches Institut,

Völklinger Strasse 49,

40221 Düsseldorf, Germany

e-mail: hellmut.mahler@polizei.nrw.de 

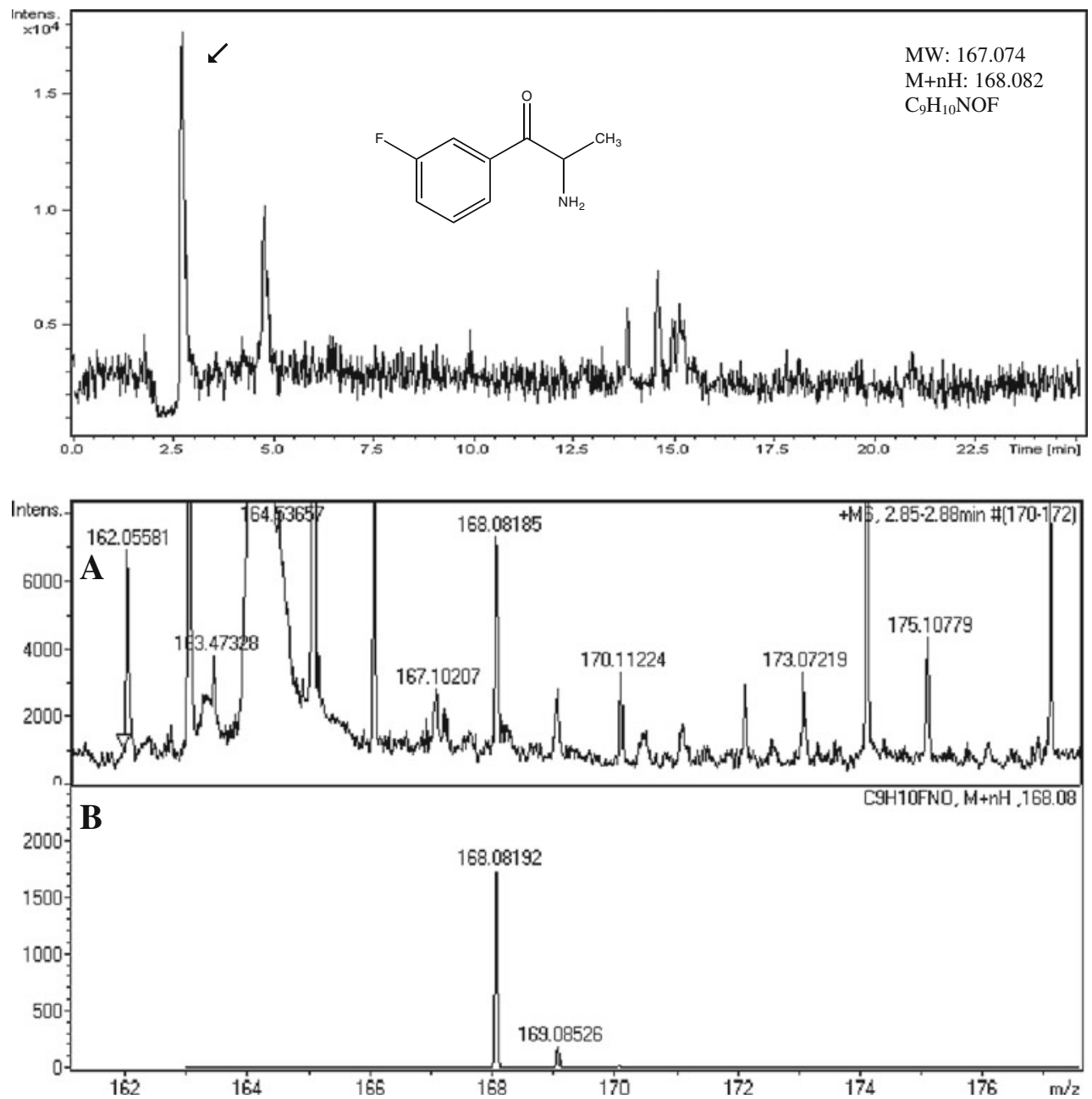

Fig. 4 LC/MS-TOF chromatogram (above) and spectra (below) of 3-fluorocathinone formed after 30 min of incubation of 3-FMC with a cryopreserved rabbit liver slice. The signal shows the $\mathrm{C}^{12}$-mass of the metabolite. a 3-Fluorocathinone mass spectrum after the incubation. b Spectrum of the calculated 3-fluorocathinone mass 